\title{
The relationship between Fusarium head blight traits, thousand-kernel weight, and
}

\section{yield in winter wheat}

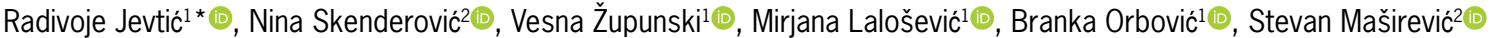

IInstitute of Field and Vegetable Crops, 30 Maksima Gorkog - 21000 - Novi Sad - Serbia.

2University of Novi Sad/Faculty of Agriculture, 8 Trg Dositeja Obradovića - 21000 - Novi Sad - Serbia.

*Corresponding author <radivoje.jevtic@ifvcns.ns.ac.rs>

Edited by: José Belasque Júnior

Received February 25, 2020

Accepted March 28, 2021

\begin{abstract}
Factors influencing Fusarium head blight (FHB) occurrence and yield losses in winter wheat have extensively been studied through the years; however, reports on the relationship between FHB traits and yield are conflicting. In addition, studies neglected the relationship between FHB traits and thousand-kernel weight (TKW). This study evaluated the variability in the relationship between FHB traits, TKW, and yield under field conditions, using 40 commercial winter wheat cultivars differing in resistance/susceptibility to FHB. In general, the FHB index had greater relation to yield, while Fusarium-damaged kernels (FDK) was more related to TKW. The relationship between yield, TKW, FHB index, and FDK was also determined by resistance/susceptibility of winter wheat cultivars. Fusarium-damaged kernels influenced yield more in moderately resistant $\left(R^{2}=43 \%\right)$ than in susceptible/moderately susceptible cultivars $\left(R^{2}\right.$ $=27 \%)$. The influence of the FHB index on TKW was weak $\left(R^{2}=9 \%\right)$ in susceptible/moderately susceptible cultivars and in moderately resistant ones $\left(R^{2}=1 \%\right)$. The potential to predict TKW from yield under pathogen pressure was limited due to the moderate-to-positive correlation between yield and TKW $(r=0.349, p<0.001)$. This study provides insights into factors that influence TKW under FHB pathogen pressure and gives direction to more efficient and reliable investigations on grain resistance toward FHB.
\end{abstract}

Keywords: FDK, FHB index, resistance

\section{Introduction}

Fusarium head blight (FHB) is one of the most devastating diseases of small grain cereals worldwide and, in Serbia, it is mainly caused by Fusarium graminearum Schwabe (sexual stage Gibberella zeae (Schwein.) Petch) (Lević et al., 2012). The main goals of breeding programs are to obtain FHB-resistance varieties as well as improve yield and quality of cereal crops. However, breeding high yield wheat varieties with good quality is not an easy task since yield and its components could be negatively correlated (Laidig et al., 2017) or not correlated at all (Mladenov et al., 2011).

Thousand-kernel weight (TKW) is one yield component associated to grain quality, related to milling quality (Protic et al., 2007). The literature reports on the relationship between FHB and yield losses (Mesterházy et al., 2015; Wegulo et al., 2011; Willyerd et al., 2012); nevertheless, investigations on factors influencing TKW losses are usually neglected in the studies. Mohammadi et al. (2012) also reported that the analysis of the simple correlations between yield and yield components without taking into account their interactions might mislead breeders.

The association of FHB index (incidence $x$ severity), Fusarium-damaged kernels (FDK), and yield of winter wheat was studied in different environments and using cultivars with different FHB reactions (Kubo et al., 2014; Mesterházy et al., 2015; Wegulo et al., 2011). However, reports show conflicts in terms of the effect of cultivars and fungicides on yield, FDK, or deoxynivalenol (DON) (Wegulo et al., 2011; Willyerd et al., 2012). In addition, Jevtić et al. (2018) reported that different environmental factors could influence yield and TKW of winter wheat, but their investigation addressed only the combined effect of foliar pathogens and abiotic factors.

As FHB has a direct effect on kernel weight and quality, contrary to indirect effect of foliar pathogens, this study hypothesized that FHB affects TKW and yield differently from reports on foliar pathogens by Jevtić et al. (2018). Hence, the main objective of this study was to investigate variability in relationship between yield, TKW, FHB index, and FDK under field conditions. To avoid oversight of variability in relationship between yield, yield components, and FHB traits, if tested with a small number of genotypes, we used 40 commercial winter wheat cultivars with varied genetic background and different levels of susceptibility/resistance to FHB.

\section{Materials and Methods}

\section{Plant material and field trial}

The data for this study originated from the response of 40 winter wheat cultivars to FHB under the field conditions. The winter wheat cultivars used in the study were predominant in the commercial production in the Republic of Serbia and their trade names were omitted to avoid any conflict of interest, since they are commercial cultivars. The trials were conducted at Rimski Šančevi in northern Serbia $\left(45^{\circ} 19^{\prime} 12^{\prime \prime} \mathrm{N}, 19^{\circ} 50^{\prime} 04^{\prime \prime} \mathrm{E}\right.$, altitude $\left.85.7 \mathrm{~m}\right)$ in two years 
(2014-2015). The mean sowing date was 20 October, the optimal time of sowing in Serbian agro-ecological conditions. The mean harvest date was 30 June of each year.

Each cultivar was sown in $5-\mathrm{m}^{2}$ plots. Conventional cultural practices were applied. Grain spawn inoculation was used to provide artificial source of Fusarium inoculum. Grain spawn inoculation was reported as the most suitable for a large uniform FHB disease nursery and for simulation of the natural infection mode (Gilbert and Woods, 2006). Corn kernel (Zea mays) inoculum was prepared with isolate $1 / 1 / 2010$ of $F$. graminearum (Institute of Field and Vegetable Crops, Novi Sad, Serbia), according to the method described by Gilber and Woods (2006). Corn kernel inoculum was spread throughout the plots at the end of tillering (three weeks prior to flowering). Isolate $1 / 1 / 2010$ was chosen as the inoculum source based on long-term pathogenicity testing under field conditions. The 15-AcDON producer of $F$. graminearum sensu stricto was identified using molecular techniques. This was of great importance knowing that one isolate can exhibit different pathogenicity potential in different years due to significant effects of the environment on DON production (Mesterházy, 2002). Since the main principle in this study was to provide uniformity in testing conditions, one isolate of $F$. graminearum was used instead of mixed population, as a mixed population consists of different strains with different pathogenic features (Mesterházy, 2002). Isolate $1 / 1 / 2010$ was identified using the specific primer pair Fg16F/R (Nicholson et al., 1998). Primer sets: GzTri7f1/ GzTri7r1, Tri7F/ Tri7DON, Tri13F/Tri13DONR, Tri303F/Tri303R, and Tri315F/Tri315R were used for multilocus chemotyping on the sequences of Tri7, Tri13, and Tri3 (Chandler et al., 2003; Jennings et al., 2004; Tok and Arslan, 2016).

The response of cultivars to infection with $F$. graminearum was determined per plot since sowing each genotype per 5- $\mathrm{m}^{2}$ plot is enough and most convenient for serial resistance testing (Mesterházy 1988, 1995, 1999, 2005). FHB traits (FHB index and FDK) were assessed on three replicates while a $1-\mathrm{m}^{2}$ subplot was considered one replicate. This provided accurate assessment of FHB traits that were further regressed with associated yield and TKW. Yield and TKW of each cultivar were measured from the entire $5-\mathrm{m}^{2}$ plot after harvest. Crops were harvested at the maturity stage $(\mathrm{BBCH} 99)$ at $15 \%$ water content.

\section{Disease assessments}

At early dough stage (BBCH 83), disease severity was scored on 100 randomly chosen spikes per subplots on each cultivar using the scale reported by Mesterházy et al. (1995). The scale was 0 - no symptoms, $25 \%=1$, 26$50 \%=2,51-75 \%=3$, and $76-100 \%=4$. The disease severity evaluated was used to calculate the FHB index.
The FHB index $(\%)$ was calculated per each subplot by taking into account disease incidence and disease severity using the Townsend-Heuberger formula (Townsend and Heuberger, 1943):

FHB index $(\%)=(\Sigma(n \times v) \div(i \times N)) \times 100$

$v=$ class of infection; $i=$ highest class of infection; $n$ $=$ number of spikes in each class; $N=$ total number of spikes.

Effect of cultivar resistance/susceptibility on the relationship between FHB index, FDK, yield, and TKW was tested on cultivars susceptible, moderately susceptible, and moderately resistant to FHB. Significance of FHB traits in resistant cultivars is negligible (Mesterházy et al., 1999); therefore, in resistant cultivars, the FHB index is small, FDK is low, and there are no significant yield losses and toxin contaminations (Mesterházy, 2002). We conducted analyses on two sets of cultivars to elucidate the effect of cultivar resistance/ susceptibility on variability in yield and TKW responses to FHB infection. One set consisted of moderately resistant cultivars and another of moderately susceptible and susceptible cultivars.

Cultivars were characterized as resistant/ susceptible to FHB infection based on statements of producers and on the average FHB index assessed in 2014, which was conductive for FHB infection (Table 1). The scale for genotype classification in categories related to their resistance/susceptibility to FHB infection was 0-5 \% - very resistant, 6-10\% - resistant, 11-25\% moderately resistant, 26-40 \% - moderately susceptible, 41-65\% - susceptible, and > $65 \%$ - very susceptible.

The proportion of Fusarium-damaged kernels (FDK) was visually scored per subplot in four replicates of 100 kernels randomly chosen after threshing 100 spikes. Shrivelled, lightweight, chalky white, or pink kernels were considered damaged kernels. FDK was calculated as FDK $(\%)=($ Number of damaged kernels / Total number of kernels) $\times 100$. Average FDK for each subplot was determined and used in the following analysis.

\section{Statistical methods}

The relationship between yield, TKW, FHB index, and FDK was analysed using multiple stepwise regression (due to data multicollinearity). Alpha to enter the predictor into the stepwise model and Alpha to remove the predictor from the stepwise model was set by default at 0.15 , value considered as limit for statistical significance. Combined effects of biotic factors (cultivar, FHB traits) and abiotic factors (year or climatic factors) were taken in consideration in all statistical analyses. Earliness, presence/absence of awns, year, and cultivar were used as categorical variable, while climatic factors and FHB traits (FHB index and FDK) were considered continuous variables. 
Table 1 - Averages of yield, thousand-kernel weight (TKW), Fusarium head blight index (FHB index), and Fusarium-damaged kernels (FDK) in 40 commercial winter wheat cultivars in 2014 and 2015.

\begin{tabular}{|c|c|c|c|c|c|c|c|c|c|c|}
\hline \multirow{2}{*}{ Cultivar } & \multirow{2}{*}{ Earliness } & \multirow{2}{*}{ Seadheads } & \multicolumn{2}{|c|}{ Yield } & \multicolumn{2}{|c|}{ TKW } & \multicolumn{2}{|c|}{ FHB index } & \multicolumn{2}{|c|}{ FDK } \\
\hline & & & 2014 & 2015 & 2014 & 2015 & 2014 & 2015 & 2014 & 2015 \\
\hline & & & \multicolumn{2}{|c|}{$-\mathrm{tha}^{-1} \longrightarrow$} & \multicolumn{2}{|c|}{$-\mathrm{g} \longrightarrow$} & \multicolumn{4}{|c|}{ 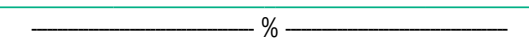 } \\
\hline 1 & Early maturing & Awnless & 4.4 & 6.7 & 26.6 & 27.6 & 16.2 & 10.0 & 28.0 & 4.0 \\
\hline 2 & Early maturing & Awnless & 4.9 & 7.1 & 37.0 & 36.0 & 24.2 & 12.0 & 20.0 & 5.0 \\
\hline 3 & Early maturing & Awned & 4.9 & 7.2 & 32.9 & 31.5 & 21.2 & 10.0 & 15.0 & 6.0 \\
\hline 4 & Early maturing & Awnless & 4.0 & 6.9 & 33.1 & 38.2 & 15.0 & 6.0 & 28.0 & 4.0 \\
\hline 5 & Early maturing & Awned & 6.9 & 6.4 & 39.8 & 38.1 & 26.0 & 6.0 & 3.0 & 2.0 \\
\hline 6 & Early maturing & Awnless & 3.5 & 4.1 & 26.9 & 26.2 & 43.6 & 10.0 & 18.0 & 6.0 \\
\hline 7 & Late maturing & Awnless & 6.8 & 9.1 & 30.7 & 31.6 & 12.6 & 6.0 & 16.0 & 3.0 \\
\hline 8 & Early maturing & Awnless & 4.7 & 7.0 & 38.9 & 38.1 & 44.8 & 20.0 & 3.0 & 6.0 \\
\hline 9 & Late maturing & Awnless & 4.1 & 5.6 & 35.8 & 36.8 & 28.0 & 8.0 & 16.0 & 3.0 \\
\hline 10 & Early maturing & Awned & 4.8 & 6.6 & 32.4 & 33.1 & 30.6 & 12.0 & 16.0 & 3.0 \\
\hline 11 & Late maturing & Awnless & 1.1 & 6.2 & 18.2 & 31.5 & 38.2 & 8.0 & 12.0 & 3.0 \\
\hline 12 & Early maturing & Awnless & 1.9 & 8.0 & 22.3 & 37.2 & 57.2 & 10.0 & 35.0 & 4.0 \\
\hline 13 & Late maturing & Awnless & 4.6 & 5.2 & 37.6 & 39.0 & 54.4 & 14.0 & 8.0 & 5.0 \\
\hline 14 & Late maturing & Awnless & 6.3 & 4.9 & 39.1 & 28.8 & 42.2 & 8.0 & 2.0 & 6.0 \\
\hline 15 & Late maturing & Awnless & 5.1 & 7.1 & 31.5 & 32.3 & 15.2 & 12.0 & 6.0 & 2.0 \\
\hline 16 & Late maturing & Awnless & 6.1 & 7.2 & 35.4 & 30.3 & 28.6 & 6.0 & 16.0 & 2.0 \\
\hline 17 & Late maturing & Awnless & 3.9 & 5.6 & 26.2 & 27.2 & 36.6 & 4.0 & 34.0 & 3.0 \\
\hline 18 & Late maturing & Awned & 5.0 & 7.4 & 29.9 & 38.6 & 26.0 & 4.0 & 30.0 & 7.0 \\
\hline 19 & Early maturing & Awnless & 7.0 & 6.6 & 34.8 & 34.0 & 26.0 & 8.0 & 8.0 & 4.0 \\
\hline 20 & Late maturing & Awnless & 3.1 & 7.2 & 26.9 & 29.7 & 47.8 & 12.0 & 36.0 & 6.0 \\
\hline 21 & Early maturing & Awned & 7.9 & 8.1 & 29.3 & 37.9 & 35.0 & 10.0 & 19.0 & 10.0 \\
\hline 22 & Late maturing & Awned & 6.9 & 7.2 & 35.4 & 33.6 & 19.0 & 8.0 & 26.0 & 5.0 \\
\hline 23 & Early maturing & Awned & 4.6 & 7.3 & 25.2 & 32.2 & 42.0 & 12.0 & 4.0 & 10.0 \\
\hline 24 & Early maturing & Awnless & 3.7 & 6.0 & 29.4 & 31.5 & 24.0 & 14.0 & 6.0 & 10.0 \\
\hline 25 & Early maturing & Awnless & 5.4 & 7.0 & 27.8 & 25.1 & 23.2 & 20.0 & 13.0 & 14.0 \\
\hline 26 & Early maturing & Awnless & 6.5 & 7.7 & 37.4 & 37.9 & 24.6 & 14.0 & 5.0 & 5.0 \\
\hline 27 & Early maturing & Awnless & 5.3 & 6.6 & 33.5 & 35.5 & 23.2 & 10.0 & 15.0 & 9.0 \\
\hline 28 & Late maturing & Awnless & 5.9 & 7.2 & 34.4 & 36.1 & 30.6 & 10.0 & 14.0 & 9.0 \\
\hline 29 & Late maturing & Awnless & 5.6 & 8.2 & 37.4 & 38.9 & 25.4 & 12.0 & 16.0 & 6.0 \\
\hline 30 & Early maturing & Awned & 1.6 & 6.1 & 21.4 & 38.6 & 29.6 & 12.0 & 1.0 & 4.0 \\
\hline 31 & Late maturing & Awned & 5.4 & 7.5 & 39.3 & 39.5 & 40.2 & 14.0 & 20.0 & 3.0 \\
\hline 32 & Late maturing & Awnless & 3.9 & 6.3 & 25.3 & 33.8 & 38.2 & 4.0 & 21.0 & 3.0 \\
\hline 33 & Early maturing & Awned & 4.2 & 7.5 & 36.6 & 35.1 & 29.6 & 18.0 & 45.0 & 10.0 \\
\hline 34 & Early maturing & Awnless & 3.7 & 8.8 & 27.1 & 32.3 & 48.4 & 16.0 & 7.0 & 9.0 \\
\hline 35 & Late maturing & Awnless & 3.5 & 7.5 & 35.0 & 36.6 & 26.2 & 8.0 & 10.0 & 8.0 \\
\hline 36 & Early maturing & Awnless & 6.4 & 7.6 & 30.4 & 30.1 & 41.6 & 12.0 & 20.0 & 9.0 \\
\hline 37 & Early maturing & Awned & 5.6 & 8.0 & 32.6 & 32.1 & 25.4 & 16.0 & 17.0 & 9.0 \\
\hline 38 & Late maturing & Awnless & 4.2 & 8.7 & 24.8 & 26.7 & 40.6 & 6.0 & 13.0 & 4.0 \\
\hline 39 & Early maturing & Awnless & 4.8 & 7.3 & 29.8 & 30.0 & 30.0 & 10.0 & 19.0 & 7.0 \\
\hline 40 & Late maturing & Awnless & 4.2 & 8.8 & 34.6 & 36.6 & 22.0 & 4.0 & 27.0 & 3.0 \\
\hline
\end{tabular}

The climatic factors analyzed in the study were monthly averages of temperatures, relative humidity, and total rainfall taken from May to June, since these months are related to anthesis, fruit development, and ripening (BBCH 61-89) of wheat in agro-ecological conditions of Serbia (http://www.hidmet.gov.rs/).

Due to the data nature, the multiple stepwise regression was performed on data transformed with $\sqrt{x+0.5}$. Coefficients of determination $\left(R^{2}\right)$ were used to determine variation percentage in the response variable explained by the model. Visualization of the significance level of factors influencing yield and TKW was performed with $-\log (\mathrm{P})$ transformation of $p$-value similarly to the Manhattan plot. The Manhattan plot is commonly used to visualize results from genome-wide association studies where each SNP (Single Nucleotide Polymorphism) has its associated $p$-value significance. The correlation between yield, TKW, and FHB traits was estimated using the Spearman coefficient of correlation and the level of significance was 0.05. Minitab 17 Statistical Software (trial version) was used for all analyses. 


\section{Results}

\section{Differences in reactions of cultivars to fluctuating climatic factors and FHB infection}

On average, the FHB index $(31 \%)$ and FDK $(18 \%)$ in 2014 were higher than the FHB index $(10 \%)$ and FDK $(3 \%)$ in 2015 (Figure 1). Average yield of 40 cultivars in 2014 (4.8 $\mathrm{t} \mathrm{ha}^{-1}$ ) was smaller than in 2015 (7.0 $\left.\mathrm{t} \mathrm{ha}^{-1}\right)$ (p $<0.001$ ) (Figure 1). Only TKW in 2014 and 2015 were not statistically different and amounted to $31.6 \mathrm{~g}$ in 2014 and $33.6 \mathrm{~g}$ in 2015 (Figure 1).

Climatic factors in 2014 and 2015 from May to June were different within a month (Table 2). In late May, total rainfall in 2015 exceeded total rainfall in 2014 by $169.2 \mathrm{~mm}$, while in early and mid-May, total rainfall in 2014 exceeded total rainfall in 2015 by $40 \mathrm{~mm}$ and $139.6 \mathrm{~mm}$, respectively. These differences made 2014 more conductive for FHB infection than 2015 (Table 2).

Cultivars differed in resistance/susceptibility to FHB, earliness, presence/absence of awns as well as in terms of yield and TKW responses on different levels of pathogen pressure in 2014 and 2015 (Table 1). The range of yield and TKW for each cultivar in 2014 and 2015 showed that some cultivars were more stable than others were, under fluctuating climatic conditions and different pathogen pressures (Figures 2A and 2B). Consequently, the chosen set of 40 cultivars provided a good basis for further analysis of relationship between yield, TKW, FHB index, and FDK.

\section{Relationship between yield, TKW, FHB index, and FDK}

The multiple linear regression showed that the most influencing factors on yield of 40 winter wheat cultivars in two-year experiment were year $(p<0.001)$, cultivar $(p$ $<0.001)$, FHB index $(p=0.029)$, and FDK $(p=0.038)$. The percentage of yield variation explained with the model and expressed by the coefficient of determination $\left(\mathrm{R}^{2}\right)$ was $78.5 \%$ with coefficient of prediction $\left(\mathrm{R}_{\text {pred }}^{2}\right)$ of $68 \%$.
$95 \% \mathrm{Cl}$ for the Mean

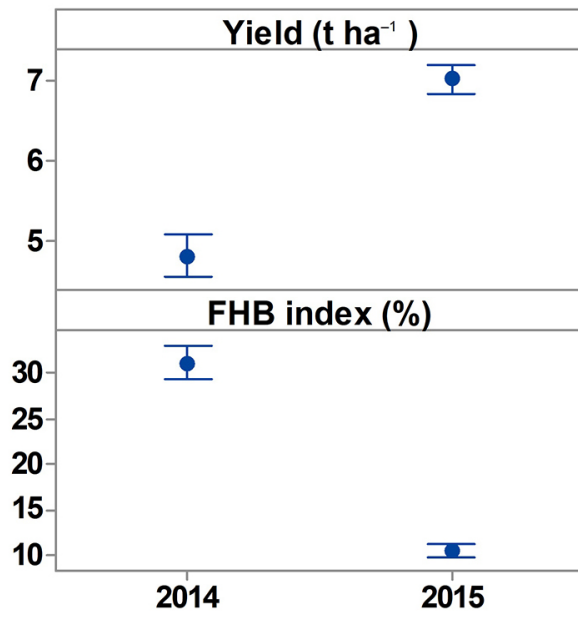

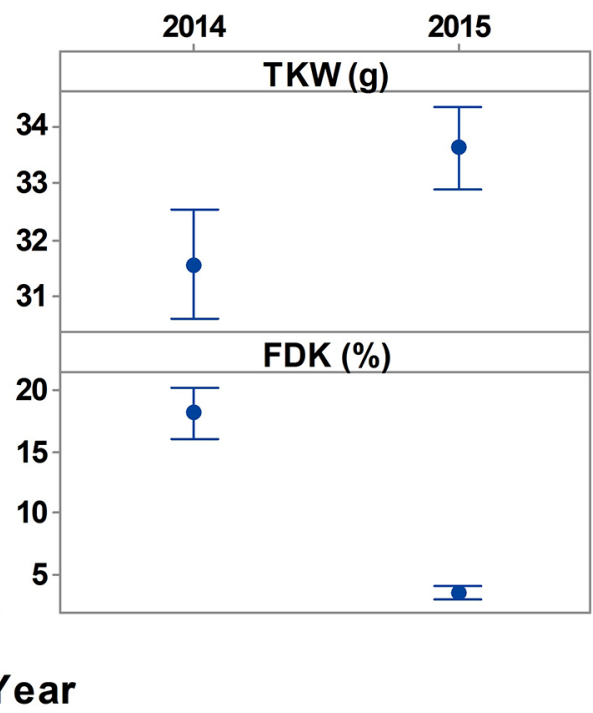

Figure 1 - Averages of yield, TKW, FHB index, and FDK in 40 winter wheat cultivars in 2014 and 2015. Fusarium head blight index (FHB index), thousand-kernel weight (TKW), and Fusarium-damaged kernels (FDK).

Table 2 - Climatic conditions in Rimski Šančevi.

\begin{tabular}{|c|c|c|c|c|c|c|c|c|}
\hline & \multicolumn{4}{|c|}{ May } & \multicolumn{4}{|c|}{ June } \\
\hline & Early & Mid & Late & & Early & Mid & Late & \\
\hline & & $\mathrm{T}\left({ }^{\circ} \mathrm{C}\right)$ & & Average & & $\mathrm{T}\left({ }^{\circ} \mathrm{C}\right)$ & & Average \\
\hline 2014 & 14.9 & 14.5 & 19.3 & 16.3 & 21 & 20 & 20.5 & 20.5 \\
\hline \multirow[t]{2}{*}{2015} & 19 & 18.9 & 16.2 & 18.0 & 23 & 21 & 18.1 & 20.7 \\
\hline & \multicolumn{3}{|c|}{ Total rainfall (mm) } & Sum & \multicolumn{3}{|c|}{ Total rainfall (mm) } & Sum \\
\hline 2014 & 47.8 & 147.6 & 6.7 & 202.1 & 3 & 8.5 & 26.7 & 38.2 \\
\hline \multirow[t]{2}{*}{2015} & 7.8 & 8 & 175.9 & 191.7 & 0 & 16.6 & 10.1 & 26.7 \\
\hline & \multicolumn{3}{|c|}{ Rel. hum. (\%) } & Average & \multicolumn{3}{|c|}{ Rel. hum (\%) } & Average \\
\hline 2014 & 73 & 80 & 71 & 74 & 62 & 71 & 69 & 67.3 \\
\hline 2015 & 64 & 65 & 82 & 71 & 65 & 73 & 74 & 71 \\
\hline
\end{tabular}



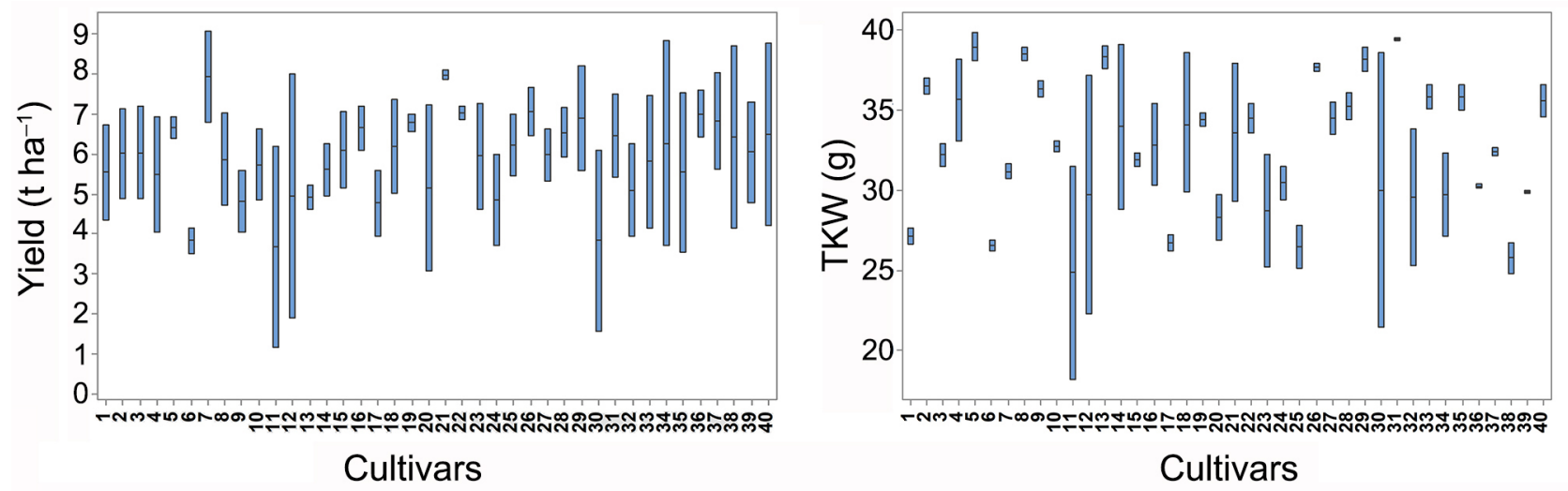

Figure 2 - Box-plot of yield (A) and TKW (B) in 40 winter wheat cultivars in 2014 and 2015.

The determining factors of TKW were: cultivar $(p<0.001)$, FHB index $(p<0.001)$, FDK $(p=0.020)$, and year $(p=0.070)$. Since Alpha to enter and Alpha to remove influencing factors in stepwise regression was set by default at 0.15 , influence of year on TKW was not significant at $p<0.05$, nor was it neglectable. TKW variation explained by the model was $75 \%$, while $\mathrm{R}_{\text {pred }}^{2}$ amounted to $63 \%$.

Greater influence of year on yield than on TKW indicated that different factors influenced yield and TKW in both years. Despite a yield component, TKW was more stable in a two-year experiment than yield itself. Correlation between yield and TKW was moderate positive $(r=0.349, p<0.001)$. Linear regression of TKW on yield in 2014-2015 showed limited potential to make TKW predictions from yield due to the low coefficient of determination $\left(\mathrm{R}^{2}=22.9 \%, p<0.001\right)$ (Figure 3 ).

Consequently, further analyses were conducted to further investigate how FHB traits and cultivar resistance/susceptibility affected yield variability and TKW responses to FHB infection in 2014-2015.

Relationship between FHB index, FDK, yield, and TKW in cultivars differing in resistance/ susceptibility to FHB infection

The effect of cultivar resistance/susceptibility on yield variability and TKW responses to FHB infection was analyzed in two sets of cultivars. One set consisted of moderately resistant cultivars and another comprised moderately susceptible and susceptible cultivars. The FHB index, FDK, and the year were used as predictor variables in both models of the multiple stepwise regression.

\section{Difference in yield association with FHB index and FDK in two sets of genotypes}

The multiple stepwise regression showed that yield of moderately resistant cultivars was influenced by the FHB index $(p=0.006)$, FDK $(p=0.045)$, year $(p<$

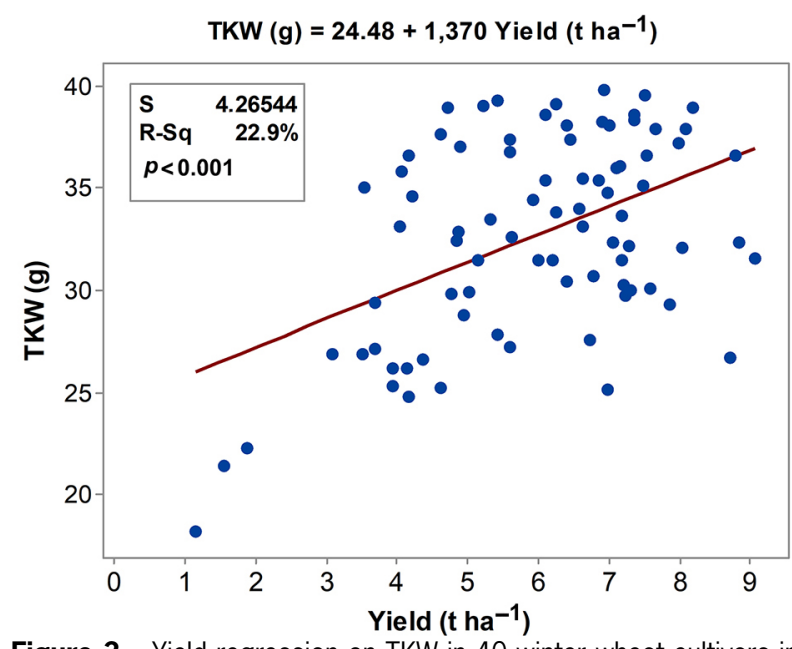

Figure 3 - Yield regression on TKW in 40 winter wheat cultivars in 2014 and 2015. Standard error of the regression (S), coefficient of determination (R-Sq), and the $p$-value for the regression model (p).

$0.001)$, and moderately resistant cultivars themselves ( $p$ $<0.001$ ). Conversely, the most influencing factors on yield of susceptible/moderately susceptible cultivars were the FHB index ( $p=0.014)$, year $(p=0.093)$, and susceptible/moderately susceptible cultivars themselves $(p<0.001)$, except for FDK.

Linear regression of FHB traits and yield in the two sets of cultivars confirmed the results of the multiple linear regression $(p<0.001)$. Yield regression on the FHB index in moderately resistant and susceptible/moderately susceptible cultivars provided $\mathrm{R}^{2}$ of $44.5 \%$ and $\mathrm{R}^{2}$ of $39.8 \%$, respectively. In addition, yield regression on FDK provided higher $\mathrm{R}^{2}$ in moderately resistant $(43 \%)$ than in susceptible/moderately susceptible cultivars (26.8\%) (Figures 4A and 4B).

These results indicated that variability in yield responses to $\mathrm{FHB}$ infection and its association with $\mathrm{FHB}$ traits differed in the two sets of cultivars. Differences were mainly related to effects of FDK and year, while 
the FHB index affected yield in the two sets of cultivars with the similar level of significance.

Variability of the FHB index $\left(\mathrm{R}^{2}=44.5 \%\right)$ and FDK $\left(\mathrm{R}^{2}=43.3 \%\right)$ affected yield variability of moderately resistant cultivars similarly; thus, both FHB traits should be treated equally in the selection of genotypes resistant FHB. Yield response to FHB in moderately resistant cultivars did not vary per year as much in the set of susceptible/moderately susceptible cultivars (Figures 5A and $5 \mathrm{~B}$ ). The range of minimum and maximum yields in 2014 was broader in susceptible/moderately susceptible genotypes (1.14-7.86 $\left.\mathrm{t} \mathrm{ha}^{-1}\right)$ than in moderately resistant genotypes (3.7-6.89 $\mathrm{t} \mathrm{ha}^{-1}$ ) (Figures 5A and 5B).

Moreover, the significant effect of year on yield of moderately resistant cultivars $(p<0.001)$ indicated that yield responses to FHB followed similar trends under different levels of pathogen pressure in 2014 and 2015, contrary to yield responses of susceptible/moderately susceptible cultivars $(p<0.093)$ (Figures 6A and 6B). However, in both sets, some genotypes (marked as 5,
19, 21 and 22) exhibited more stable yield responses to FHB than others although they were exposed to a broad range of pathogen pressure in both years and fluctuating climatic factors in the period of anthesis (Figures 6A and $6 \mathrm{~B}$, Table 1). The FHB index of genotype marked as 22 was less than $25 \%$, while the FHB index of the others exceeded $25 \%$.

\section{Difference in TKW association with the FHB index and FDK in two sets of genotypes}

TKW of moderately resistant cultivars was influenced only by FDK $(p<0.001)$ and cultivars themselves ( $p$ $<0.001$ ), excluding the FHB index and year, indicating that TKW of moderately resistant cultivars was more influenced by FDK than the FHB index. Conversely, TKW of susceptible/moderately susceptible cultivars was influenced by both FDK $(p=0.091)$ and the FHB index $(p=0.008)$, as well as by the cultivars themselves $(p<0.001)$.
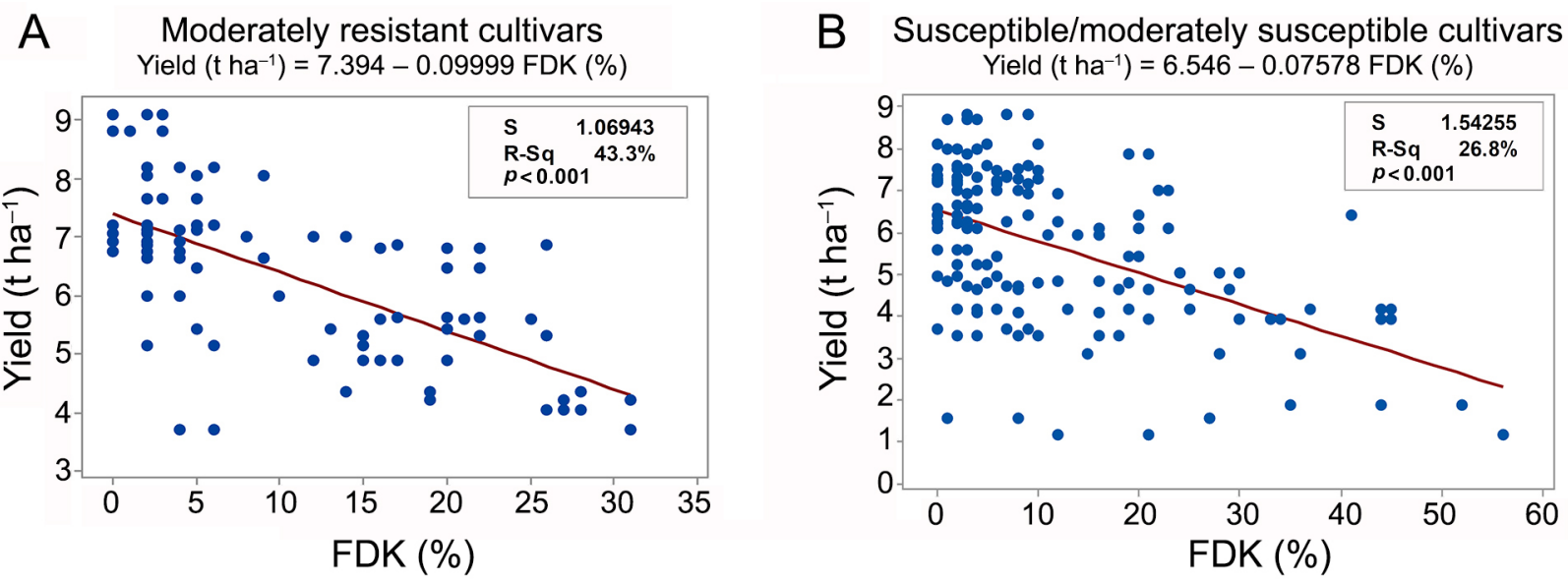

Figure 4 - FDK regression on yield in moderately resistant cultivars (A) and susceptible/moderately susceptible cultivars (B) in 2014 and 2015. Standard error of the regression (S), coefficient of determination (R-Sq), and the $p$-value for the regression model ( $p$ ).

\section{A}

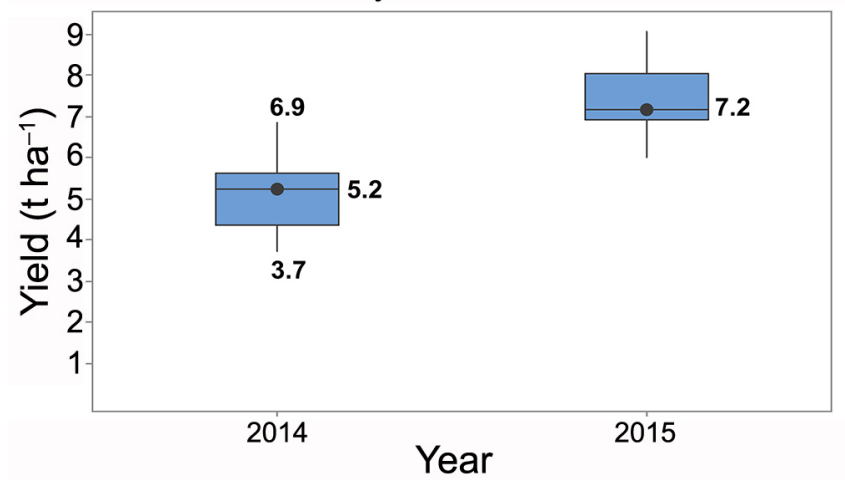

B Susceptible/moderately susceptible cultivars

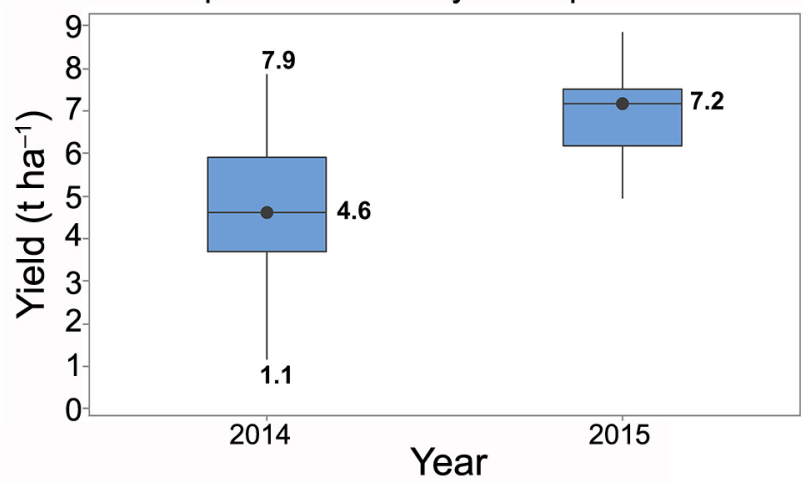

Figure 5 - Box-plot of yield responses on FHB in moderately resistant cultivars (A) and susceptible/moderately susceptible cultivars (B). Box plot presented minimal, median and maximal values of yield responses on FHB. 
Although the FHB index significantly affected TKW in susceptible/moderately susceptible genotypes, regression of the FHB index on TKW showed quite low association $\left(\mathrm{R}^{2}=8.8 \%, p<0.001\right)$ similar to moderately resistant cultivars $\left(\mathrm{R}^{2}=1 \%, p<0.001\right)$ (Figures $7 \mathrm{~A}$ and $\left.7 \mathrm{~B}\right)$.

Since cultivar resistance/susceptibility affects relationship between the FHB index, FDK, yield, and TKW, the relationship between the FHB index and FDK was also tested in relation to cultivars showing different FHB reactions.

\section{Effect of cultivar resistance/susceptibility on the relationship between the FHB index and FDK}

In this study, year and cultivars were determining factors for both FHB index and FDK $(p<0.001)$. The FHB index in 2014 ranged between 12.6 and $57.2 \%$ and from 4 to $20 \%$ in 2015. The FDK range in 2014 was $0-56 \%$ and $0-14 \%$ in 2015 .

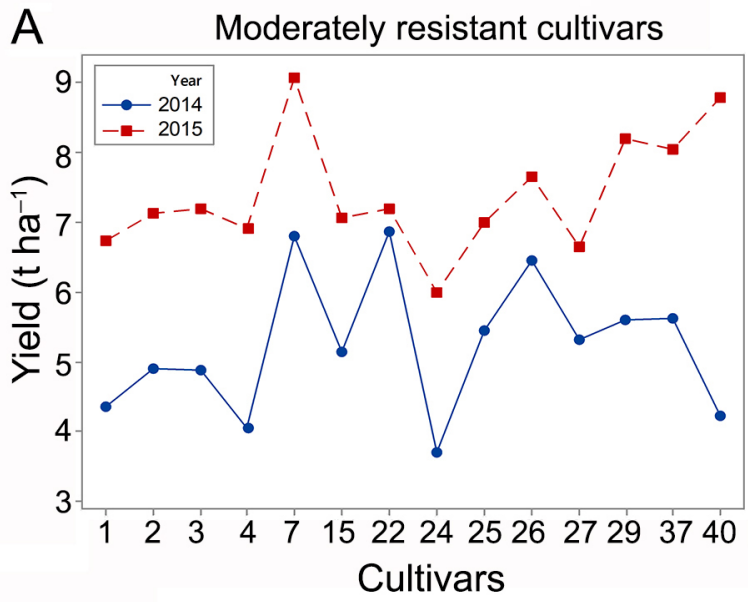

The coefficient of correlation between the FHB index and FDK in susceptible and moderately susceptible $(\mathrm{r}=0.667, p<0.001)$, as well as in moderately resistant cultivars $(\mathrm{r}=0.705, p<0.001)$, was moderate and positive. When the FHB index and FDK were linearly regressed using two sets of cultivars, similar coefficients of determination were found for both moderately resistant $\left(\mathrm{R}^{2}=42 \%, p<0.001\right)$ and susceptible/moderately susceptible cultivars $\left(\mathrm{R}^{2}=39 \%\right.$, $p<0.001$ ) (Figures 8A and 8B).

\section{Discussion}

This study aimed to elucidate the relationship between the FHB index, FDK, TKW in field conditions testing 40 commercial winter wheat cultivars with divergent genetic backgrounds. Our results presented insights into factors influencing TKW, which was mostly underestimated in studies on the FHB effect on winter

B Susceptible/moderately susceptible cultivars

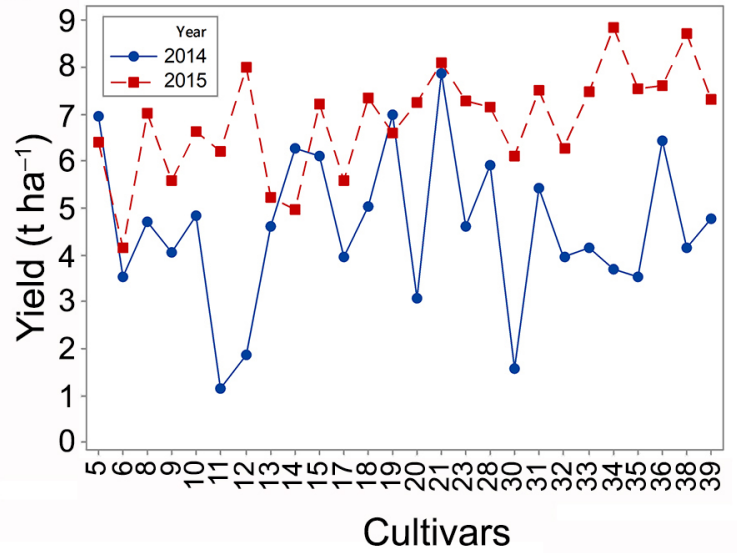

Figure 6 - Trends in yield responses on FHB in 2014 and 2015 in moderately resistant cultivars (A) and susceptible/moderately susceptible cultivars (B).
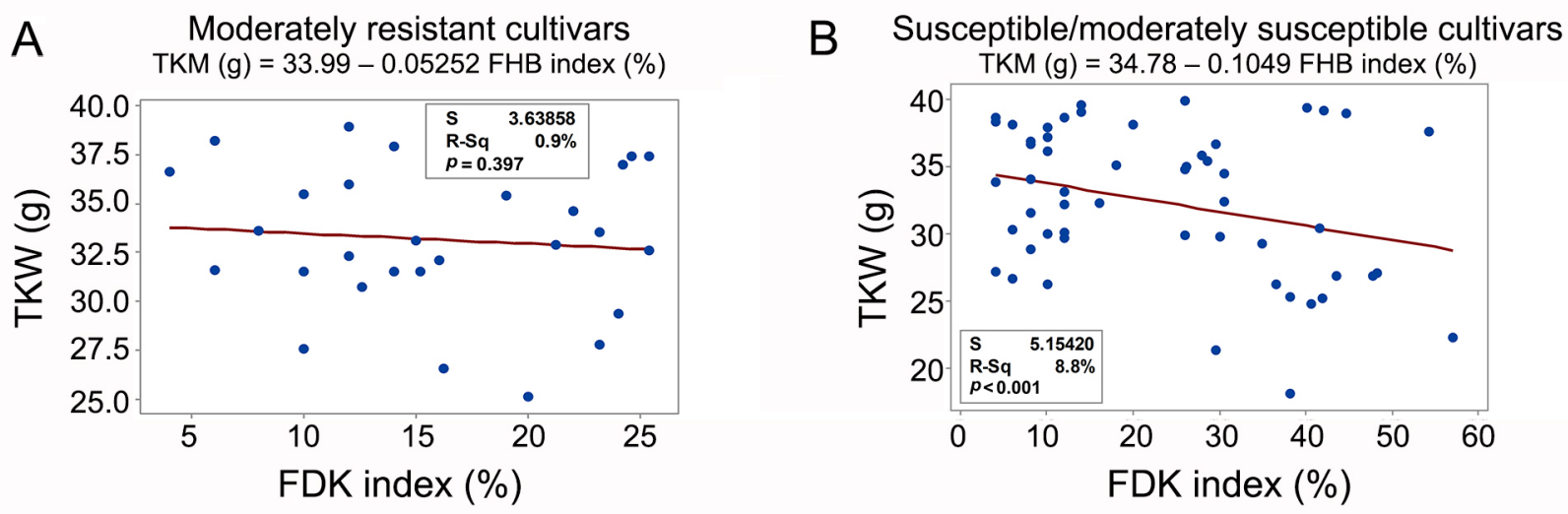

Figure 7 - FHB regression on TKW in 2014 and 2015 in moderately resistant cultivars (A) and susceptible/moderately susceptible cultivars (B). Standard error of the regression (S), coefficient of determination (R-Sq), and the $p$-value for the regression model $(p)$. 

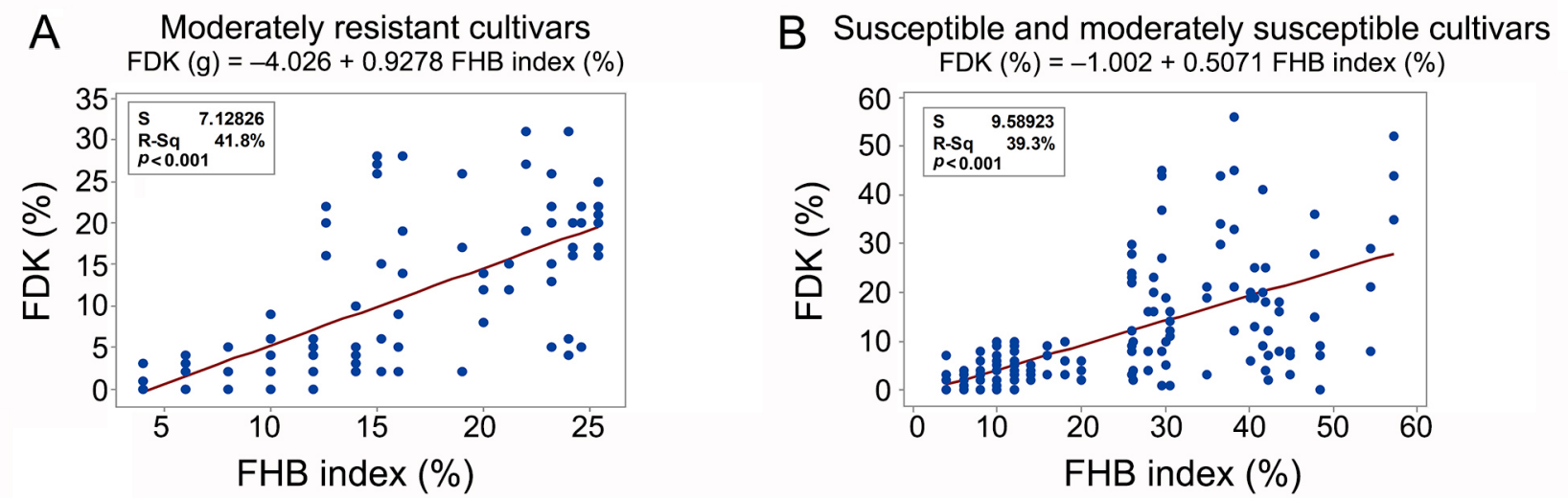

Figure 8 - The FHB index regression on FDK in 2014 and 2015 in moderately resistant cultivars (A) and (B) susceptible/moderately susceptible cultivars. Standard error of the regression (S), coefficient of determination (R-Sq), and the $p$-value for the regression model ( $p$ ).

wheat cultivars. The results showed that relationship between TKW and yield was not straightforward, TKW and yield regressed differently with FHB traits, and each genotype showed specific range of pathogen pressure that could be tolerated with non-significant influence on the expression of yield potential.

In our study, TKW and yield of winter wheat cultivars had moderate positive correlation $(\mathrm{r}=0.349$, $p<0.001$ ) and TKW, although a yield component was more stable in a two-year experiment than yield itself. In the season favourable for FHB, year had greater influence on yield than on TKW. Linear regression of TKW on yield in 2014-2015 showed limited potential to make predictions of TKW of yield due to the low coefficient of determination $\left(\mathrm{R}^{2}=22.9 \%, p<0.001\right)$. Jevtić et al. (2018) reported a similar $R^{2}$ of $11-22 \%$ for linear regression between yield and TKW; however, their investigation was focused on combined effect of foliar pathogens and abiotic factors on yield and TKW of winter wheat. Factors related to the period before and right after anthesis are more critical for yielding than factors occurring in the grain filling period when kernel weight is defined (Herrera-Foessel et al., 2006); thus, moderate positive correlation between yield and TKW comes from partially or non-correlated changes in factors affecting wheat development at different growth stages. Harasim et al. (2016) also reported that TKW contributed to grain yield from -0.4 to $13.3 \%$ in different growing seasons; however, the authors did not specify which factor had significant influence on those differences. This study investigated the influencing factors on yield and TKW through the effect of FHB traits (FHB index and FDK) and year in two sets of genotypes. One set consisted of moderately resistant and the other of susceptible/moderately susceptible cultivars on FHB infection.

In general, yield was more related to the FHB index, while TKW was more related with FDK; however, the relationship between yield, TKW, FHB index, and FDK was also determined by resistance/susceptibility of winter wheat cultivars. In moderately resistant cultivars, yield variation per growing season was not as prominent as in susceptible/moderately susceptible cultivars. This study indicated that variability of yield responses on FHB in moderately resistant cultivars was associated to both the FHB index and FDK, contrary to variability in yield responses of susceptible/moderately susceptible cultivars, which was significantly associated only to the FHB index. Consequently, the FHB index should not be considered as the key trait in the selection of moderately resistant cultivars to $\mathrm{FHB}$, but a trait that should be accompanied with others, such as FDK.

The need to assess the FHB index and FDK in testing of yield response in moderately resistant cultivars can be partly explained by the fact that different genetic backgrounds determine resistance to FHB. Some QTLs, separately or in combination, determine the resistance to the FHB index, FDK, and DON (Buerstmayr et al., 2009; Mesterházy et al., 2015). In general, there are five types of wheat resistance to FHB: resistance to initial infection (type I), resistance to spread (type II), resistance to DON accumulation (type III), resistance to kernel infection (type IV), and tolerance (type V) (Mesterházy et al., 1999). However, Martin et al. (2017) noted that different resistance types are partly interdependent and independently inherited, which was confirmed by other authors (Bai et al., 2000; Langevin et al., 2004; Mesterházy et al., 1999; Mesterházy, 2002).

Partial dependence of the FHB index on FDK was also indicated in this study, since variability of the FHB index could not be fully explained by FDK variability. In both moderately resistant and susceptible/moderately susceptible genotypes, the FHB index and FDK were moderately correlated and showed similar coefficients of determination of $\left(\mathrm{R}^{2}=42 \%, p<0.001\right)$ and $\left(\mathrm{R}^{2}=\right.$ $39 \%, p<0.001)$, respectively. This was in accordance with the FHB-FDK correlation of $r=0.451$ reported by Mesterházy et al. (2015). However, Wegulo et al. (2011) noted that the relationship between the FHB index and FDK was stronger in moderately resistant 
than in susceptible cultivars. The difference between the results may be because we tested more cultivars than Wegulo et al. (2011) did; thus, greater diversity of genetic background of cultivars could have influenced the result. The relationship between DON accumulation and grain infection in not expected to follow a clear trend (Martin et al., 2017; He et al., 2019); thus, more attention should be placed on the future of physiological responses of genotypes on combined abiotic and biotic stressors to elucidate association of FHB index and FDK and their effect on yield in moderately resistant and susceptible/moderately susceptible genotypes.

The effect of regulatory network for plant responses to abiotic and biotic stresses consists of many components, which may function antagonistically or synergistically in respect to plant responses to pathogens (Kissoudis et al., 2014; Glazebrook et al., 2005; Yasuda et al., 2008). In this study, each genotype tolerates a specific range of pathogen pressure with non-significant difference in expression of yield potential. One moderately resistant and three susceptible/moderately susceptible cultivars showed yield stability in both growing seasons, although they were exposed to a broad range of pathogen pressure in both growing seasons and fluctuating climatic factors in the period of anthesis. These genotype-specific yield responses of both moderately resistant as well as susceptible/moderately susceptible genotypes under FHB infection indicated that more attention should be placed on the transcriptome analysis of susceptible genotype responses at different level of FHB pressure and their association with yield achievements. Pan et al. (2018) reported that defense mechanisms to FHB are genotype-specific and that each resistant genotypes exibited differences in expression profiles after analysis of transcriptome association with resistance to FHB.

Similar to different responses of yield to FHB traits in moderately resistant and susceptible/moderately susceptible cultivars, the association of TKW with FHB traits in two sets of cultivars also differed. FDK on TKW showed a significant effect in both sets of genotypes and it can be explained by poor grain filling under pathogen pressure caused by deterioration of transport of assimilates affecting grain composition (Martin et al., 2017). However, in this study, FDK variability was more related to TKW variability in moderately resistant than in susceptible/moderately susceptible cultivars. This study also indicated low association between the FHB index and TKW in both sets of cultivars, and not prominent effect of year on TKW variability, highlighting that more attention should be placed to the effect of cultivars on variability of this yield component.

This study showed that the level of resistance/ susceptibility of genotypes influenced variability in yield and TKW responses to FHB traits. Phenotyping in plant breeding is always an important practice, since determination of genetic variability may not always explain complexity of phenotype markers and complete QTL interactions are difficult to identify and breed
(Velu and Singh, 2013). Therefore, this study provided basis for improvement of the screening methods for resistance responses of wheat genotypes to FHB by indicating the differences in the relationships between yield, TKW, and FHB traits. It also suggested that the level of pathogen pressure that triggers susceptible reaction of varieties is specific for each cultivar and has to be further investigated to assess grain resistance toward FHB, more efficiently and reliably.

\section{Acknowledgments}

This paper was carried out as a part of the project TR 31066-Contemporary breeding of small grains for current and future needs financed by the Ministry of Education, Science and Technological Development of the Republic of Serbia.

\section{Authors' Contributions}

Conceptualization: Jevtić, R. Data acquisition: Skenderović, N.; Lalošević, M.; Orbović, B. Data analysis: Župunski, V.; Skenderović, N.; Lalošević, M. Design of Methodology: Jevtić, R.; Skenderović, N.; Lalošević, M. Writing and editing: Župunski, V.; Jevtić, R.; Lalošević, M.; Skenderović, N.; Maširević, S.

\section{References}

Bai, G.H.; Shaner, G.; Ohm, H. 2000. Inheritance of Resistance to Fusarium graminearum in Wheat. Theoretical and Applied Genetics 100: 1-8.

Buerstmayr, H.; Ban, T.; Anderson, J.A. 2009. QTL mapping and marker-assisted selection for Fusarium head blight resistance in wheat: a review. Plant Breeding 128: 1-26.

Chandler, E.A.; Duncan, R.S.; Thomsett, M.A.; Nicholson, P. 2003. Development of PCR assays to Tri7 and Tri13 and characterisation of chemotypes of Fusarium graminearum, Fusarium culmorum and Fusarium cerealis. Physiological and Molecular Plant Pathology 62: 355-367.

Gilbert, J.; Woods S.M. 2006. Strategies and considerations for multilocation FHB screening nurseries. International Scab Nursery Consortium 3: 93-102.

Glazebrook, J. 2005. Contrasting mechanisms of defense against biotrophic and necrotrophic pathogens. Annual Review of Phytopathology 43: 205-227.

Harasim, E.; Wesołowski, M.; Kwiatkowski, C.; Harasim, P.; Staniak, M.; Feledyn-Szewczyk, B. 2016. The contribution of yield components in determining the productivity of winter wheat (Triticum aestivum L.). Acta Agrobotanica 69: 1675.

He, X.; Dreisigacker, S.; Singh, R.P.; Singh, P.K. 2019. Genetics for low correlation between Fusarium head blight disease and deoxynivalenol (DON) content in a bread wheat mapping population. Theoretical and Applied Genetics 132: 2401-2411.

Herrera-Foessel, S.A.; Singh, R.P.; Huerta-Espino, J.; Crossa, J.; Yuen, J.; Djurle, A. 2006. Effect of leaf rust on grain yield and yield traits of durum wheats with race-specific and slow rusting resistance to leaf rust. Plant Disease 90: 1065-1072. 
Jennings, P.; Coates, M.E.; Walsh, K.; Turner, J.A.; Nicholson, P. 2004. Determination of deoxynivalenol- and nivalenolproducing chemotypes of Fusarium graminearum isolated from wheat crops in England and Wales. Plant Pathology 53: 643652.

Jevtić, R.; Župunski, V.; Lalošević, M.; Mladenov, N.; Orbović, B. 2018. The combined effects of multiple diseases and climatic conditions on thousand kernel weight losses in winter wheat. European Journal of Plant Pathology 152: 469-477.

Kissoudis, C.; van de Wiel, C.; Visser, R.G.F.; van der Linden, G. 2014. Enhancing crop resilience to combined abiotic and biotic stress through the dissection of physiological and molecular crosstalk. Frontiers in Plant Science 5: 207.

Kubo, K.; Kawada, N.; Nakajima, T.; Hirayae, K.; Fujita, M. 2014. Field evaluation of resistance to kernel infection and mycotoxin accumulation caused by Fusarium head blight in western Japanese wheat (Triticum aestivum L.) cultivars. Euphytica 200: 81-93.

Laidig, F.; Piepho, H-P.; Rentel, D.; Drobek, T.; Meyer, U.; Huesken, A. 2017. Breeding progress, environmental variation and correlation of winter wheat yield and quality traits in German official variety trials and on-farm during 1983-2014. Theoretical and Applied Genetics 130: 223-245.

Langevin, F.; Eudes, F.; Comeau, A. 2004. Effect of trichothecenes produced by Fusarium Graminearum during Fusarium head blight development in six cereal species. European Journal of Plant Pathology 110: 735-746.

Lević, J.; Stanković, S.; Krnjaja, V.; Tančić, S.; Ivanović, D.; Bočarov-Stančić, A. 2012. Relationships of mycobiota on rachides and kernels of wheat. European Journal of Plant Pathology 134: 249-256.

Martin, C.; Schöneberg, T.; Vogelgsang, S.; Vincenti, J.; Bertossa, M.; Mauch-Mani, B.; Mascher, F. 2017. Factors of wheat grain resistance to Fusarium head blight. Phytopathologia Mediterranea 56: 154-166.

Mesterházy, Á. 1988. Expression of resistance of wheat to Fusarium graminearum and $F$. culmorum under various experimental conditions. Journal of Phytopathology 123: 304-310.

Mesterházy, Á. 1995. Types and components of resistance against fusarium head blight of wheat. Plant Breeding 114: 377-386.

Mesterházy, Á.; Bartók, T.; Mirocha, C.M.; Komoróczy, R. 1999. Nature of resistance of wheat to Fusarium head blight and deoxynivalenol contamination and their consequences for breeding. Plant Breeding 118: 97-110.

Mesterházy, Á. 2002. Role of deoxynivalenol in aggressiveness of Fusarium graminearum and F. culmorum and in resistance to Fusarium head blight. European Journal of Plant Pathology 108: 675-684.

Mesterházy, Á.; Bartók, T.; Kászonyi, G.; Varga, M.; Tóth, B.; Varga, J. 2005. Common resistance to different Fusarium spp. causing fusarium head blight in wheat. European Journal of Plant Pathology 112: 267-281.

Mesterházy, Á.; Lehoczki-Krsjak, S.; Varga, M.; Szabó-Hevér, Á.; Tóth, B.; Lemmens, M. 2015. Breeding for FHB resistance via Fusarium damaged kernels and deoxynivalenol accumulation as well as inoculation methods in winter wheat. Agricultural Sciences 6: 970-1002.
Mladenov, N.; Hristov, N.; Kondic-Spika, A.; Djuric,V.; Jevtic, R.; Mladenov, V. 2011. Breeding progress in grain yield of winter wheat cultivars grown at different nitrogen levels in semiarid conditions. Breeding Science 61: 260-268.

Mohammadi, M.; Sharifi, P.; Karimizadeh, R.; Shefazadeh, M.K. 2012. Relationships between grain yield and yield components in bread wheat under different water availability (dryland and supplemental irrigation conditions). Notulae Botanicae Horti Agrobotanici Cluj-Napoca 40: 195-200.

Nicholson, P.; Simpson, D.R.; Weston, G.; Rezanoor, H.N.; Lees, A.I.; Parry, D.W.; Joyce, D. 1998. Detection and quantification of Fusarium culmorum and Fusarium graminearum in cereals using PCR assays. Physiological and Molecular Plant Pathology 53: $17-37$.

Pan, Y.; Liu, Z.; Rocheleau, H.; Fauteux, F.; Wang, Y.; McCartney, C.; Ouellet, T. 2018. Transcriptome dynamics associated with resistance and susceptibility against fusarium head blight in four wheat genotypes. BMC Genomics 19: 642 .

Protic, R.; Jovin, P.; Protic, N.; Jankovic, S.; Jovanovic, Ž. 2007. Mass of 1,000 grains in several winter wheat genotypes, at different dates of sowing and rates of nitrogen fertilizer. Romanian Agricultural Research 24: 39-42.

Tok, F.M.; Arslan, M. 2016. Distribution and genetic chemotyping of Fusarium graminearum and Fusarium culmorum populations in wheat fields in the eastern Mediterranean region of Turkey. Biotechnology \& Biotechnological Equipment 30: 254-260.

Townsend, G.R.; Heuberger, J.V. 1943. Methods for estimating losses caused by diseases in fungicide experiments. Plant Disease Report 27: 340-343.

Velu, G.; Singh, R.P. 2013. Phenotyping in wheat breeding. p. 41-71. In: Panguluri, S.K.; Kumar, A.A., eds. Phenotyping in plant breeding: applications of phenotyping methods for crop improvement. Springer, New York, NY, USA.

Wegulo, S.N.; Bockus, W.W.; Hernandez Nopsa, J.; De Wolf, E.D.; Eskridge, K.M.; Peiris, K.H.S.; Dowell, F.E. 2011. Effects of integrating cultivar resistance and fungicide application on Fusarium head blight and deoxynivalenol in winter wheat. Plant Disease 95: 554-560.

Willyerd, K.T.; Li, C.; Madden, L.V.; Bradley, C.A.; Bergstrom, G.C.; Sweets, L.E.; McMullen, M.; Ransom, J.K.; Grybauskas, A.; Osborne, L.; Wegulo, S.N.; Hershman, D.E.; Wise, K.; Bockus, W.W.; Groth, D.; Dill-Macky, R.; Milus, E.; Esker, P.D.; Waxman, K.D.; Adee, E.A.; Ebelhar, S.E.; Young, B.G.; Paul, P.A. 2012. Efficacy and stability of integrating fungicide and cultivar resistance to manage Fusarium head blight and deoxynivalenol in wheat. Plant Disease 96: 957-967.

Yasuda, M.; Ishikawa, A.; Jikumaru, Y.; Seki, M.; Umezawa, T.; Asami, T. 2008. Antagonistic interaction between systemic acquired resistance and the abscisic acid-mediated abiotic stress response in Arabidopsis. Plant Cell 20: 1678-1692. 